\title{
The synthesis of the 2,3-difluorobutan-1,4-diol diastereomers
}

\author{
Robert Szpera, Nadia Kovalenko, Kalaiselvi Natarajan, Nina Paillard and Bruno Linclau*
}

\author{
Full Research Paper \\ Address: \\ Chemistry, University of Southampton, Highfield, Southampton SO17 \\ 1BJ, United Kingdom \\ Email: \\ Bruno Linclau* - bruno.linclau@soton.ac.uk \\ * Corresponding author

\section{Keywords:} \\ acetal isomerization; deoxyfluorination; epoxide opening; fluorinated \\ building block; vicinal difluoride
}

Open Access

\author{
Beilstein J. Org. Chem. 2017, 13, 2883-2887.
}

doi:10.3762/bjoc. 13.280

Received: 05 October 2017

Accepted: 13 December 2017

Published: 27 December 2017

This article is part of the Thematic Series "Organo-fluorine chemistry IV".

Guest Editor: D. O'Hagan

(c) 2017 Szpera et al.; licensee Beilstein-Institut.

License and terms: see end of document.

\begin{abstract}
The diastereoselective synthesis of fluorinated building blocks that contain chiral fluorine substituents is of interest. Here we describe optimisation efforts in the synthesis of anti-2,3-difluorobutane-1,4-diol, as well as the synthesis of the corresponding syndiastereomer. Both targets were synthesised using an epoxide opening strategy.
\end{abstract}

\section{Introduction}

The introduction of fluorine in organic compounds usually results in the modification of a range of chemical, physical and biological properties [1]. Fluorine incorporation is therefore a common strategy to optimise the properties of drugs/agrochemicals, as well as materials [2-6].

Many methods exist for the stereoselective introduction of the C-F group [7-11]. An alternative and often time-efficient approach is the use of fluorinated building blocks, where fluorine is introduced as part of a carbon containing fragment, sometimes also bearing other functionality $[12,13]$. The development of novel fluorinated building blocks is therefore of interest, particularly those that can be synthesised conveniently on a multigram scale. Interestingly, the majority of currently commercially available fluorinated building blocks do not contain stereogenic $\mathrm{C}-\mathrm{F}$ bonds.

The vicinal-difluoride motif is known to exert conformational control through the fluorine gauche effect $[14,15]$, and so building blocks containing this motif are of interest $[16,17]$. We have previously reported on the gram-scale synthesis of meso-2,3difluorobutane-1,4-diol (anti-5) starting from commercially available cis-but-2-ene-1,4-diol (Scheme 1) [17]. The vicinaldifluoride group was introduced by a two-step sequence, with initial nucleophilic epoxide [18] opening by a fluoride source [19], followed by nucleophilic deoxyfluorination [9-11]. 


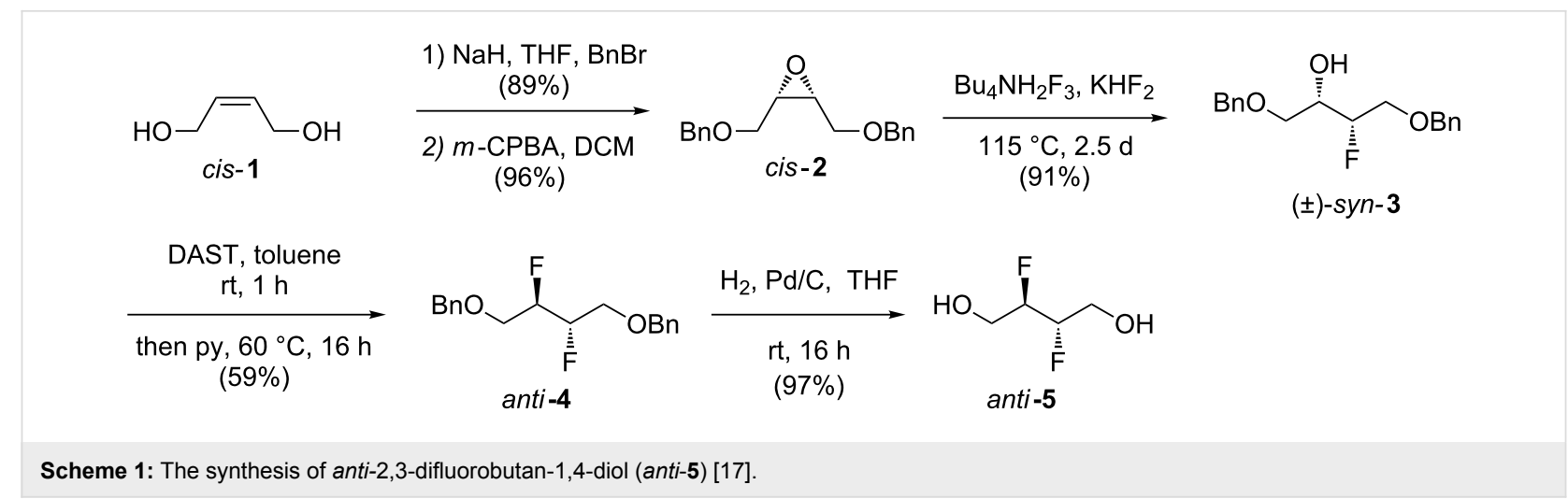

In this contribution, we report on work directed at the further optimisation of the synthesis of anti-5, as well as on a gramscale synthesis of its diastereomer $( \pm)-s y n-5$, a novel compound.

\section{Results and Discussion Optimisation of the synthesis of anti-5}

While the synthesis of anti-5 as described in Scheme 1 was high-yielding [17], two disadvantages were apparent. First, the epoxide opening takes 2.5 days at $115^{\circ} \mathrm{C}$ and uses an expensive fluoride source (Landini's reagent [18]: $\mathrm{Bu}_{4} \mathrm{NH}_{2} \mathrm{~F}_{3}$ ). It was found that $\mathrm{Bu}_{4} \mathrm{NH}_{2} \mathrm{~F}_{3}$ made in-house gave significantly reduced yields. Second, the use of the benzyl ether protecting group resulted in a significant increase in mass, and therefore, chromatographic purification of the protected intermediates upon scale-up was inconvenient.

As previously reported [17], epoxide opening of cis-2 with Olah's reagent (HF-py) led to an $80 \%$ yield of the fluorohydrin after just three hours, however, the product was obtained as a mixture of both the syn- and anti-diastereomers. Whilst no mechanistic studies were conducted, it is possible that competing $\mathrm{S}_{\mathrm{N}} 1$ and/or anchimeric assistance by the benzyloxy group occurred. Work by Schlosser has shown that 1,2-disubstituted epoxide opening with $\mathrm{Et}_{3} \mathrm{~N} \cdot 3 \mathrm{HF}$ proceeds with excellent diastereoselectivity [19]. $\mathrm{Et}_{3} \mathrm{~N} \cdot 3 \mathrm{HF}$ is less acidic than Olah's reagent, disfavouring $\mathrm{S}_{\mathrm{N}} 1$ and rearrangement pathways [20,21] Indeed, the use of this reagent for the epoxide opening of cis-2 led to $( \pm$ )-syn-3 in excellent yield (Scheme 2), with no significant isomerisation (see Supporting Information File 1). Epoxide opening with the recently described $\mathrm{TBAF} / \mathrm{KHF}_{2}$ [22] was also possible, but in lower yield (75\%, not shown). Incidentally, it was also found that the subsequent deoxofluorination reaction was somewhat higher yielding when DAST was added at rt over just $5 \mathrm{~min}$, immediately followed by the addition of pyridine and heating at $70^{\circ} \mathrm{C}$.

It should be noted that DAST is known to undergo decomposition at temperatures above $90{ }^{\circ} \mathrm{C}$ [23]. Here we use DAST in solution. The initial mixing is at room temperature, and heating doesn't exceed $70{ }^{\circ} \mathrm{C}$, and therefore, the procedure is deemed to have low risk. Nonetheless, care must be taken and the reaction was run with the protection of a blast shield.

In order to reduce the relative contribution of the protecting group to the overall weight of the intermediates, the use of an acetonide was explored. Given the starting alkene was cis-configured, its introduction was possible from the start (Scheme 3).

Hence, following literature procedures [24-26], the reaction of cis-1 with 2,2-dimethoxypropane and subsequent epoxidation led to 7. However, epoxide opening with $\mathrm{Et}_{3} \mathrm{~N} \cdot 3 \mathrm{HF}$ was accompanied by acetonide rearrangement to afford fluorohydrin $( \pm)-\mathbf{9}$, containing the thermodynamically favoured five-membered ring [24]. This is clearly indicated by the appearance of a doublet of doublets for the primary alcohol $\mathrm{OH}$ proton. DAST-mediated deoxofluorination then led to $( \pm)-\mathbf{1 0}$, in which an alkyl fluoride signal at $-232 \mathrm{ppm}$ confirmed the presence of a primary fluoride.

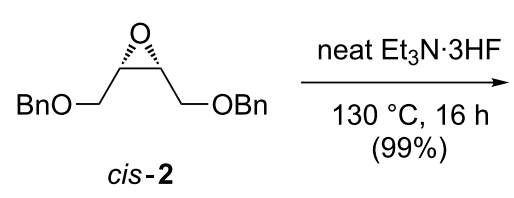

cis-2

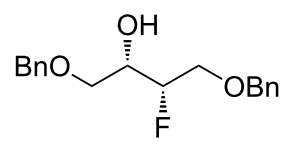

$( \pm)-$ syn-3

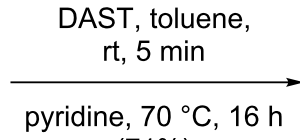

$(71 \%)$<smiles>FC(COCc1ccccc1)C(F)COc1ccccc1</smiles>

anti-4 

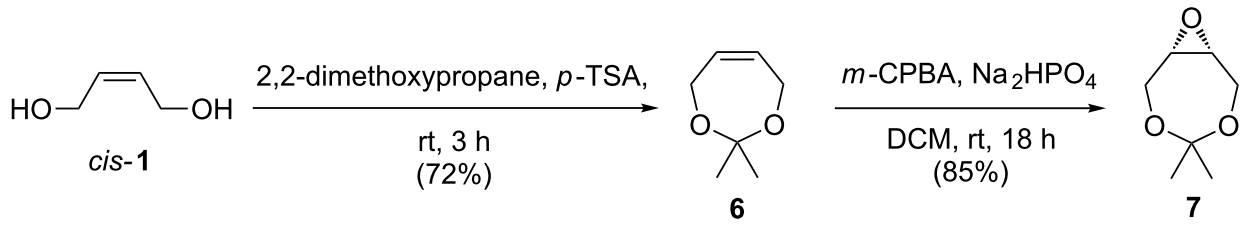

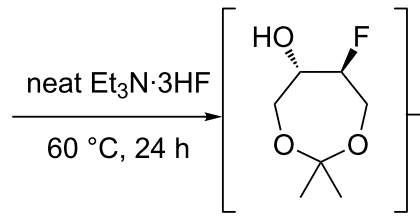

$( \pm)-8$

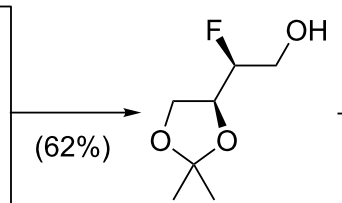

$( \pm)-9$

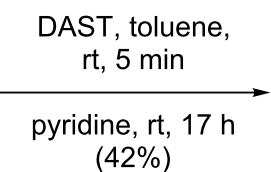

$(42 \%)$

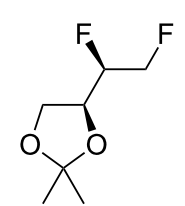

$( \pm)-10$

Scheme 3: Attempted synthesis of anti-5 via acetonide protection.

Hence, non-acidic epoxide opening conditions were investigated to circumvent the rearrangement (Scheme 4). Both the use of $\mathrm{Bu}_{4} \mathrm{NH}_{2} \mathrm{~F}_{3}$ [18] and of the $\mathrm{TBAF} / \mathrm{KHF}_{2}$ reagent combination [22] were successful (56\% and 64\%, respectively). While subsequent fluorination using PyFluor only led to the formation of the 2-pyridinesulfonate intermediate $( \pm)-\mathbf{1 2}$, the use of DAST at $60{ }^{\circ} \mathrm{C}$ proved successful. The difluoride meso-11 was not isolated due to its low boiling point, but was immediately subjected to acid hydrolysis to give anti-5. Unfortunately, the yield for this two-step process was only moderate $(30 \%)$.

\section{Synthesis of ( \pm )-syn-5}

The synthesis of $( \pm)-s y n-5$ (Scheme 5) was achieved starting from the trans-configured but-2-ene-1,4-diol (1), which is not commercially available in geometrically pure form.<smiles>CC1(C)OCC2O[C@H]2CO1</smiles>
$\mathrm{KHF}_{2}, 115^{\circ} \mathrm{C}, 20 \mathrm{~h}$ $\mathrm{Bu}_{4} \mathrm{NH}_{2} \mathrm{~F}_{3}(56 \%)$ or TBAF $(64 \%)$<smiles>CC1(C)OCC(O)C(F)CO1</smiles>

$( \pm)-8$

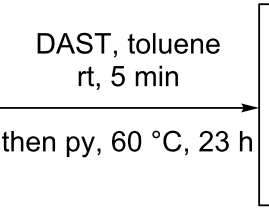
rt, $5 \mathrm{~min}$<smiles>CC1(C)OC[C@@H](F)[C@H](F)CO1</smiles>

meso-11 $\underset{\substack{\mathrm{Et}_{2} \mathrm{O} \\(30 \%)}}{2 \mathrm{M} \mathrm{HCl}}$

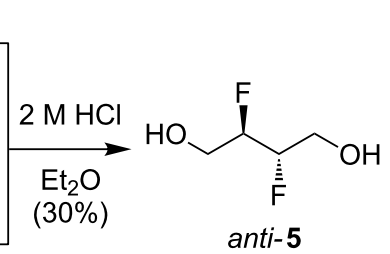

anti-5

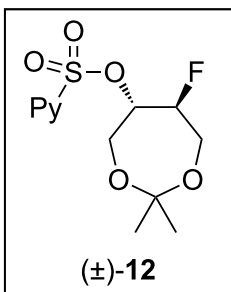

Scheme 4: Completion of the synthesis of anti-5.

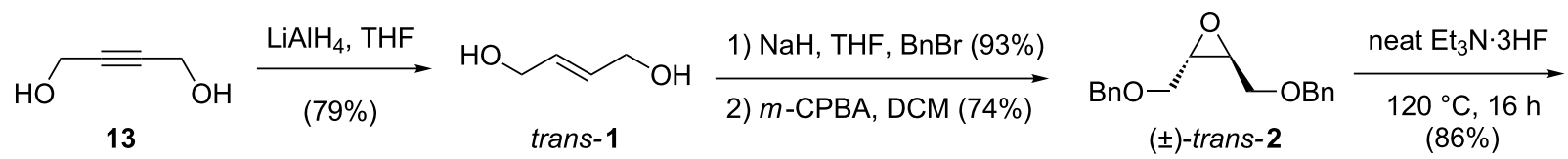<smiles>O[C@H](COCc1ccccc1)[C@@H](F)COc1ccccc1</smiles>

( \pm )-anti-3<smiles>FC(COCc1ccccc1)C(F)COc1ccccc1</smiles>

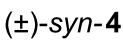
$\mathrm{dr}=98: 2$

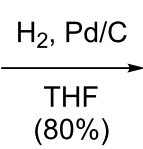

$(80 \%)$<smiles>OCC(F)C(F)CO</smiles>

(士)-syn-5 
Hence, according to literature procedures, reduction of 1,4butynediol (13) by $\mathrm{LiAlH}_{4}$ to give trans-1 [27] was followed by benzylation [28] and epoxidation with $m$-CPBA to give $( \pm)$-trans-2 [28]. When the reaction was performed on a small scale, excess $m$-CPBA and the byproduct 3-chlorobenzoic acid were removed by extraction with a saturated $\mathrm{Na}_{2} \mathrm{~S}_{2} \mathrm{O}_{3}$ solution However, on scale-up this proved inconvenient due to the large volumes of solvent required, and so these impurities were precipitated out the reaction mixture by cooling to $0{ }^{\circ} \mathrm{C}$ and collected by filtration through Celite. After work-up, the obtained epoxide was of high purity and no additional chromatographic purification was required, which was convenient on scale. The reaction of $( \pm)$-trans-2 with neat $\mathrm{Et}_{3} \mathrm{~N} \cdot 3 \mathrm{HF}$ at $120^{\circ} \mathrm{C}$ for $16 \mathrm{~h}$ led, after aqueous work-up, to $( \pm)$-anti-3 in high diastereomeric purity (see Supporting Information File 1). The ${ }^{19} \mathrm{~F}$ shift of $-195.3 \mathrm{ppm}$ is different compared to that of $( \pm)$-syn-3 $(-204.4 \mathrm{ppm})$ [17]. Upon scale-up of the reaction to $10 \mathrm{~g}$ of $( \pm)$-trans-2, a similarly high yield of $90 \%$ (crude) was obtained, which again could be used directly in the next step without purification. Conversion of fluorohydrin $( \pm)$-anti-3 to difluoride $( \pm)$-syn-4 under the same conditions as shown in Scheme 2 resulted in $56 \%$ yield after column chromatography. ${ }^{19} \mathrm{~F}$ NMR analysis of the crude product showed a dr of 98:2 in favour of $( \pm)$-syn-4. However, given a diastereomerically pure starting material was used, this indicates that $\mathrm{S}_{\mathrm{N}} 1$ or neighbouring group participation pathways may have occurred, although only to a very small extent. Separation of the diastereomers proved not possible. Finally, deprotection of $( \pm)-s y n-4$ by palladium catalysed hydrogenolysis led to $( \pm)-s y n-5$. Recrystallization to remove the minor diastereomer was not successful.

\section{Conclusion}

A gram-scale synthesis of both syn- and anti-2,3-difluorobutan1,4-diol diastereomers is described. The key steps involve epoxide opening and subsequent deoxyfluorination. For the first step, $\mathrm{Et}_{3} \mathrm{~N} \cdot 3 \mathrm{HF}$ was found to be the best reagent, giving an excellent yield with no formation of diastereomeric byproducts. Unfortunately it was found that the subsequent DAST-mediated deoxyfluorination gives rise to a small amount of the undesired diastereomer. The primary alcohol groups require protection, for which the benzyl group has been employed. While this group is effective for this purpose, there is a significant mass increase upon its introduction (roughly three fold increase). An investigation to use the much smaller acetonide protecting group, which can be used for the cis-1,4-butenediol starting material, was carried out. It was found that the use of $\mathrm{Et}_{3} \mathrm{~N} \cdot 3 \mathrm{HF}$ for the epoxide opening step also lead to acetal rearrangement, leading to a more stable 1,3-dioxolane ring. While the use of $\mathrm{Bu}_{4} \mathrm{NH}_{2} \mathrm{~F}_{3} / \mathrm{KHF}_{2}$ and $\mathrm{TBAF} / \mathrm{KHF}_{2}$ achieves epoxide opening without acetonide rearrangement, the subsequent deoxyfluorination/deprotection sequence is low yielding (30\%). Overall, the protocols provided will be of use for the large-scale synthesis of both syn- and anti-2,3-difluorobutan-1,4-diol building blocks.

\section{Supporting Information}

\section{Supporting Information File 1}

Experimental part and NMR spectra.

[http://www.beilstein-journals.org/bjoc/content/

supplementary/1860-5397-13-280-S1.pdf]

\section{Acknowledgements}

We thank the University of Southampton and the EPSRC (core capability EP/K039466/1) for funding.

\section{ORCID ${ }^{\circledR}$ iDs}

Robert Szpera - https://orcid.org/0000-0003-1351-1750 Nina Paillard - https://orcid.org/0000-0003-0109-5403

Bruno Linclau - https://orcid.org/0000-0001-8762-0170

\section{References}

1. Gillis, E. P.; Eastman, K. J.; Hill, M. D.; Donnelly, D. J.; Meanwell, N. A. J. Med. Chem. 2015, 58, 8315. doi:10.1021/acs.jmedchem.5b00258

2. Zhou, Y.; Wang, J.; Gu, Z.; Wang, S.; Zhu, W.; Aceña, J. L.; Soloshonok, V. A.; Izawa, K.; Liu, H. Chem. Rev. 2016, 116, 422. doi:10.1021/acs.chemrev.5b00392

3. Wang, J.; Sánchez-Roselló, M.; Aceña, J. L.; del Pozo, C.; Sorochinsky, A. E.; Fustero, S.; Soloshonok, V. A.; Liu, H. Chem. Rev. 2014, 114, 2432. doi:10.1021/cr4002879

4. Fujiwara, T.; O'Hagan, D. J. Fluorine Chem. 2014, 167, 16. doi:10.1016/j.jfluchem.2014.06.014

5. O'Hagan, D. J. Fluorine Chem. 2010, 131, 1071. doi:10.1016/j.jluchem.2010.03.003

6. Kirsch, P.; Bremer, M. ChemPhysChem 2010, 11, 357. doi:10.1002/cphc.200900745

7. Champagne, P. A.; Desroches, J.; Hamel, J.-D.; Vandamme, M.; Paquin, J.-F. Chem. Rev. 2015, 115, 9073. doi:10.1021/cr500706a

8. Liang, T.; Neumann, C. N.; Ritter, T. Angew. Chem., Int. Ed. 2013, 52, 8214. doi:10.1002/anie.201206566

9. Yerien, D. E.; Bonesi, S.; Postigo, A. Org. Biomol. Chem. 2016, 14, 8398. doi:10.1039/C6OB00764C

10. Al-Maharik, N.; O'Hagan, D. Aldrichimica Acta 2011, 44, 65.

11. Hu, W.-L.; Hu, X.-G.; Hunter, L. Synthesis 2017, 49, 4917. doi:10.1055/s-0036-1590881

12. Percy, J. M. Building Block Approaches to Aliphatic Organofluorine Compounds. In Organofluorine Chemistry: Techniques and Synthons; Chambers, R. D., Ed.; Topics in Current Chemistry, Vol. 193; Springer: Berlin, Heidelberg, 1997; pp 131-196.

13. Harsanyi, A.; Sandford, G. Org. Process Res. Dev. 2014, 18, 981. doi:10.1021/op500141c

14. Thiehoff, C.; Rey, Y. P.; Gilmour, R. Isr. J. Chem. 2017, 57, 92. doi:10.1002/ijch.201600038

15. Hunter, L. Beilstein J. Org. Chem. 2010, 6, No. 38. doi:10.3762/bjoc.6.38

16. O'Hagan, D.; Rzepa, H. S.; Schüler, M.; Slawin, A. M. Z. Beilstein J. Org. Chem. 2006, 2, No. 19. doi:10.1186/1860-5397-2-19 
17. Linclau, B.; Leung, L.; Nonnenmacher, J.; Tizzard, G. Beilstein J. Org. Chem. 2010, 6, No. 62. doi:10.3762/bjoc.6.62

18. Landini, D.; Penso, M. Tetrahedron Lett. 1990, 31, 7209. doi:10.1016/S0040-4039(00)97281-2

19. Hamatani, T.; Matsubara, S.; Matsuda, H.; Schlosser, M. Tetrahedron 1988, 44, 2875. doi:10.1016/S0040-4020(88)90023-3

20. Haufe, G. J. Fluorine Chem. 2004, 125, 875. doi:10.1016/j.jluchem.2004.01.023

21. Wölker, D.; Haufe, G. J. Org. Chem. 2002, 67, 3015 doi:10.1021/jo016331r

22. Yan, N.; Lei, Z.-W.; Su, J.-K.; Liao, W.-L.; Hu, X.-G. Chin. Chem. Lett. 2016, 28, 467. doi:10.1016/j.cclet.2016.10.006

23. Lal, G. S.; Pez, G. P.; Pesaresi, R. J.; Prozonic, F. M.; Cheng, H. J. Org. Chem. 1999, 64, 7048. doi:10.1021/jo990566+

24. Elliott, W. J.; Fried, J. J. Org. Chem. 1976, 41, 2469. doi:10.1021/jo00876a027

25. Al-Dulayymi, A.; Li, X.; Neuenschwander, M. Helv. Chim. Acta 2000, 83, 1633

doi:10.1002/1522-2675(20000705)83:7<1633::AID-HLCA1633>3.0.CO ;2-5

26. Mischitz, M.; Kroutil, W.; Wandel, U.; Faber, K. Tetrahedron: Asymmetry 1995, 6, 1261. doi:10.1016/0957-4166(95)00158-L

27. Organ, M. G.; Cooper, J. T.; Rogers, L. R.; Soleymanzadeh, F.; Paul, T. J. Org. Chem. 2000, 65, 7959. doi:10.1021/jo001045I

28. Hachiya, I.; Matsumoto, T.; Inagaki, T.; Takahashi, A.; Shimizu, M. Heterocycles 2010, 82, 449. doi:10.3987/COM-10-S(E)16

\section{License and Terms}

This is an Open Access article under the terms of the Creative Commons Attribution License (http://creativecommons.org/licenses/by/4.0), which permits unrestricted use, distribution, and reproduction in any medium, provided the original work is properly cited.

The license is subject to the Beilstein Journal of Organic Chemistry terms and conditions:

(http://www.beilstein-journals.org/bjoc)

The definitive version of this article is the electronic one which can be found at: $\underline{\text { doi: } 10.3762 / \text { bjoc. } 13.280}$ 